\title{
The changing face of paediatric diabetes
}

\author{
Amy S. Shah ${ }^{1,2} \cdot$ Kristen J. Nadeau ${ }^{3,4}$
}

Received: 23 September 2019 / Accepted: 26 November 2019/Published online: 2 January 2020

(C) Springer-Verlag GmbH Germany, part of Springer Nature 2020

\begin{abstract}
The purpose of this review is to provide an update on the changing face of paediatric type 1 diabetes and type 2 diabetes. Paediatric diabetes is on the rise, with extensive research dedicated to understanding its pathophysiology, comorbidities and complications. As obesity continues to increase among all youth, differentiating between type 1 diabetes and type 2 diabetes has become increasingly difficult but remains important for optimising treatment, anticipating complications and predicting disease risk. Novel treatments are emerging, with the ultimate goal being to achieve glycaemic control, limit weight gain, improve quality of life and reduce comorbidities. In this review, we focus on updates regarding the epidemiology, clinical presentation, comorbidities and complications of paediatric type 1 diabetes and type 2 diabetes and conclude with current and emerging treatments.
\end{abstract}

Keywords Complications $\cdot$ Diabetes $\cdot$ Insulin $\cdot$ Metformin $\cdot$ Paediatrics $\cdot$ Review $\cdot$ Type 1 diabetes $\cdot$ Type 2 diabetes

$\begin{array}{ll}\text { Abbreviations } & \\ \text { DKA } & \text { Diabetic ketoacidosis } \\ \text { DKD } & \text { Diabetic kidney disease } \\ \text { GLP-1 } & \text { Glucagon-like peptide-1 } \\ \text { MBS } & \text { Metabolic bariatric surgery } \\ \text { MDI } & \text { Multiple daily injections } \\ \text { RISE } & \text { Restoring Insulin Secretion } \\ \text { RYGB } & \text { Roux-en Y gastric bypass } \\ \text { SGLT2 } & \text { Sodium-glucose cotransporter 2 } \\ \text { Teen-LABS } & \text { Teen-Longitudinal Assessment of Bariatric } \\ & \text { Surgery }\end{array}$

Electronic supplementary material The online version of this article (https://doi.org/10.1007/s00125-019-05075-6) contains a slide of the figure for download, which is available to authorised users.

Amy S. Shah

amy.shah@cchmc.org

1 University of Cincinnati, Department of Pediatrics, Cincinnati, $\mathrm{OH}$, USA

2 Cincinnati Children's Hospital Medical Center, Division of Endocrinology, 3333 Burnet Ave, ML 7012, Cincinnati, OH 45229, USA

3 University of Denver, Department of Pediatrics, Aurora, CO, USA

4 Children's Hospital Colorado, Division of Endocrinology, Aurora, CO, USA
TODAY Treatment Options for Type 2 Diabetes in Adolescents and Youth

TZD Thiazolidinedione

This review provides an update on paediatric type 1 and type 2 diabetes. Type 1 diabetes is typically characterised by insulin deficiency and is thought to result when an environmental trigger initiates an autoimmune response to the pancreatic beta cells in a genetically susceptible individual [1]. On the other hand, youth onset type 2 diabetes is typically characterised by insulin resistance followed by varying degrees of beta cell failure [2]. While $10-20 \%$ of individuals with type 1 diabetes have a family member with type 1 diabetes, more than $90 \%$ of youth with type 2 diabetes have a relative with type 2 diabetes [3]. Both genetics and the environment are thought to contribute to the risk of type 1 and type 2 diabetes, though a recent study found that heritability did not contribute to the variance of type 2 diabetes among twins diagnosed before 45 years of age [4]. Viral infections, diet, exposure to maternal diabetes in utero, endocrine disruptors and obesity have each been linked to diabetes, the latter most strongly linked to type 2 diabetes [5].

\section{Epidemiology}

The incidence of type 1 diabetes in youth varies according to geography, age, sex and ethnicity and continues to increase worldwide at a rate of $1-3 \%$ per year [6]. The highest incidences 
of type 1 diabetes occur in Sweden and Finland (37-65 per 100,000 children) with a slight male predominance (3:2 male to female ratio in incidence at age $\geq 13$ years) $[7,8]$. Venezuela and parts of China have the lowest incidence $(<2$ per 100,000 children) [9]. In the USA, the incidence of type 1 diabetes among non-Hispanic white children and adolescents was 27 per 100,000 per year in 2012 [10]. The incidence in African-American and Hispanic children was $50-70 \%$ of that of non-Hispanic white children ( $\sim 19$ and 15 per 100,000 per year, respectively) and lowest in Native American and Asian/Pacific Islander youth (6.5 per 100,000 per year) [10], with largely no overall differences by sex [10]. Parts of Canada, such as Newfoundland, have a higher incidence of type 1 diabetes (36 per 100,000 per year) than the USA [11].

The annual increase of youth-onset type 2 diabetes in the USA is currently $4.8 \%$ [10]. The rise in type 2 diabetes largely parallels the rise in childhood obesity and in 2012 the estimated incidence in the USA was 12.5 per 100,000 children. The largest increases have been observed in non-Hispanic black, Native American and Asian/Pacific Islander youth, followed by Hispanic youth, with a low and stable incidence in non-Hispanic white youth from 2002 to 2012 [10]. In the USA, youth-onset type 2 diabetes is twice as common in females as in males [10]. Youth-onset type 2 diabetes is seen across the world in both developed and under developed nations [12]. In India and Japan nearly 50\% of youth-onset diabetes $(<25$ years old) is attributed to type 2 diabetes, with type 2 diabetes diagnosed twice as often as type 1 diabetes among adolescents $[13,14]$.

\section{Clinical presentation}

Establishing the type of diabetes is important for choosing the best treatment, anticipating complications and predicting disease risk in relatives. Typical characteristics of youth with type 1 diabetes, type 2 diabetes and MODY are shown in Table 1 [15].

Youth with type 1 diabetes are more likely to be white and to present with polyuria, polydipsia, polyphagia and weight loss [16]. Features of the metabolic syndrome are rare unless significant obesity is also present. Diabetic ketoacidosis (DKA) is seen in up to $50 \%$ of youth at presentation $[17,18]$. Forty-five per cent of children present with type 1 diabetes before 10 years of age [19] but there are two peaks in the age of presentation, the first at 4-6 years and the second at 10-14 years.

Type 2 diabetes should be considered in pubertal youth with obesity, a family history of type 2 diabetes, features of the metabolic syndrome, and absent pancreatic autoantibodies. In the Treatment Options for Type 2 Diabetes in Adolescents and Youth (TODAY) study, of the 699 youth with type 2 diabetes enrolled, $97 \%$ of youth were overweight/ obese, $90 \%$ had a family history of type 2 diabetes and only $20 \%$ were non-Hispanic white [3]. At enrolment, a third of youth with type 2 diabetes had an elevated blood pressure or hypertension (BP $>90$ th percentile for age, sex and height), $80 \%$ had low HDL-cholesterol $(<1.03 \mathrm{mmol} / \mathrm{l})$, and $21 \%$ had elevated triacylglycerol levels $(>1.69 \mathrm{mmol} / \mathrm{l})$ [3].

Polydipsia and polyuria are seen in about $67 \%$ of youth with type 2 diabetes at presentation, while a third are diagnosed through routine screening of asymptomatic youth with obesity [18]. DKA and hyperglycaemic hyperosmolar state are present at diagnosis in $6-11 \%$ and $2 \%$ of youth with type 2 diabetes, respectively $[17,18]$. Median age of type 2 diabetes presentation is 13.5 years, coinciding with the peak of puberty and physiological insulin resistance, with an earlier presentation in girls vs boys due to sex differences in the age of pubertal onset $[3,18,20]$. Pre-pubertal children rarely have type 2 diabetes, even if obese [3, 18, 20].

In overweight youth, the clinical presentations of type 1 and type 2 diabetes may overlap [21]. Currently $36 \%$ of youth with type 1 diabetes in the USA are overweight or obese $(22.9 \%$ overweight, $13.1 \%$ obese), and the frequency is higher among female youth (40.8\% overweight or obese), based on data from 5529 adolescents in the Type 1 Diabetes Exchange, a large USbased clinical registry [21]. Youth with type 1 diabetes in Germany, Austria and Canada also show high BMI $z$ scores compared with youth without diabetes [22]. Insulin resistance, while usually present in type 2 diabetes, is also seen in many youth and adults with type 1 diabetes [23-25].

C-peptide level can be helpful in differentiating between diabetes types but may be low at diagnosis of type 2 diabetes and normal during the honeymoon phase of type 1 diabetes. However, 2 years following a diagnosis of diabetes, the Cpeptide level is generally still modestly elevated in people with type 2 diabetes, while in type 1 diabetes individuals it is usually low.

Screening for diabetes autoantibodies is recommended in all individuals with clinically suspected type 2 diabetes to help to differentiate it from type 1 diabetes [26, 27]. Of the 1206 youth with a clinical diagnosis of type 2 diabetes screened in the TODAY study, $118(\sim 10 \%)$ had GAD65, insulin and/or insulinoma-associated antigen 2 (IA-2) autoantibodies [28]. The presence of antibodies suggests autoimmune type 1 diabetes and predicts a more rapid decline in beta cell function and higher risk for development of other autoimmune disorders [29]. Ninety per cent of youth who develop type 1 diabetes before puberty have islet antibodies detectable before age 5 years [30], with a peak onset of antibody emergence at age 2 years. Progression to type 1 diabetes at 10 year follow-up after islet autoantibody seroconversion in 585 children with multiple islet autoantibodies was $69.7 \%$ (95\% CI $65.1 \%$, $74.3 \%$ ), and in 474 children with a single islet autoantibody was $14.5 \%$ (95\% CI 10.3\%, 18.7\%) [31]. Risk scores to predict the diagnosis of type 1 diabetes based on type and concentration of antibody are available [32].

The US SEARCH for Diabetes in Youth study developed an aetiological approach to classifying diabetes types in youth 
Table 1 Classical presentation of diabetes types in children and adolescents

\begin{tabular}{llll}
\hline & Classical type 1 diabetes & Classical type 2 diabetes & Monogenic diabetes \\
\hline Age at presentation & Two peaks: age 4-6 years and 10-14 years & $\begin{array}{l}\text { Onset after puberty, rare before } \\
\text { age 10 years }\end{array}$ & $\begin{array}{l}\text { Onset before age 25 years } \\
\text { Weight }\end{array}$ \\
& $\begin{array}{l}\text { Usually normal weight, can be } \\
\text { overweight or obese }\end{array}$ & $90 \%$ are overweight or obese & $\begin{array}{l}\text { Usually normal weight, can be } \\
\text { overweight or obese }\end{array}$ \\
Autoantibodies & Present & Absent & Absent \\
Insulin resistance & Less common & Present & Absent \\
Risk of DKA & High & Low & Low \\
C-peptide after diagnosis & Low & Detectable & Detectable \\
Family history of diabetes & Infrequent (10-15\%) & Frequent (90\%) & Frequent, usually in multiple generations \\
\hline
\end{tabular}

based on the presence of autoimmunity and insulin resistance (estimated by waist circumference, serum triacylglycerol and $\mathrm{HbA}_{1 \mathrm{c}}$ ) [15]. Using this method, $70 \%$ of youth aligned with traditional descriptions of type 1 diabetes (autoimmune positive, 'insulin sensitive') or type 2 diabetes (non-autoimmune, 'insulin resistant'). However, $20 \%$ of their cohort had autoimmune positivity with 'insulin resistance', likely representing youth with type 1 diabetes plus obesity and/or family history of type 2 diabetes, and $10 \%$ of youth were non-autoimmune and 'insulin sensitive', a group requiring further testing for other types of diabetes such as MODY.

\section{Youth-onset vs adult-onset type 2 diabetes}

Compared with adults, youth with type 2 diabetes appear to have a more severe phenotype with greater reductions in insulin sensitivity and insulin clearance, higher insulin secretion, a more rapid decline in beta cell function overtime (measured by hyperglycaemic clamp), and overall poorer responses to medical treatments [33-39]. In the TODAY study where treatment with metformin alone, metformin plus lifestyle intervention, or metformin plus rosiglitazone was compared, treatment failure (defined as an $\mathrm{HbA}_{1 \mathrm{c}}$ of $>64 \mathrm{mmol} / \mathrm{mol}$ [ $>8 \%$ ] or metabolic decompensation requiring insulin therapy) [40] occurred in $52 \%, 39 \%$ and $47 \%$ of youth, respectively. Treatment failure for all three arms occurred within 11 months on average [41], with an estimated annual rate of beta cell function decline of $\approx 20-35 \%$ [42]. This is in stark contrast to adults with type 2 diabetes in A Diabetes Outcome Progression Trial (ADOPT), where metformin treatment failure rates were $21 \%$, less than half of the $52 \%$ reported in TODAY [43] and where the rate of decline in beta cell function was only $7-11 \%$ per year.

The Restoring Insulin Secretion (RISE) study included both adults and youth, allowing for direct comparisons of beta cell function using oral glucose tolerance tests and hyperglycaemic clamps in people with impaired glucose tolerance (prediabetes) or recently diagnosed type 2 diabetes. At baseline, despite similar BMI and dysglycaemia, youth in the RISE study demonstrated $50 \%$ lower insulin sensitivity than adults as well as augmented beta cell responses even after accounting for insulin sensitivity, suggesting greater demand on beta cells compared with adults [34, 35]. Furthermore, when youth were evaluated on or after 12 months of treatment with metformin alone or insulin glargine followed by metformin, youth experienced a deterioration of beta cell function that continued after treatment withdrawal. In contrast, beta cell function in the adults improved during treatment, although it was not sustained after treatment withdrawal [33, 36]. These studies highlight differences in beta cell function outcomes and responses to medications by age group and point to a more adverse trajectory of beta cell deterioration in youth.

\section{Comorbidities and complications}

Data from the SEARCH study consistently show a higher prevalence of comorbidities in young adults with type 2 diabetes vs type 1 diabetes, even after adjusting for established cardiovascular risk [44, 45]. At age 21 years, those with type 2 diabetes vs type 1 diabetes showed higher rates of diabetic kidney disease (DKD), retinopathy, peripheral neuropathy, arterial stiffness and hypertension [46, 47] (Fig. 1). There is clear evidence of elevated left ventricular mass, abnormal cardiac geometry and impaired diastolic function, reduced cardiopulmonary fitness, abnormal limb blood flow, arterial stiffness and higher blood pressure, as well as renal hyperfiltration, in both diabetes types compared with peers without diabetes with a similar BMI [24, 48-59]. However, some comorbidities including low HDL-cholesterol and elevated triacylglycerol, hepatic fat [54] and liver transaminases [60], and non-alcoholic steatohepatitis (NASH) [61] are not typically present in youth with type 1 diabetes, especially in those with a normal BMI. Moreover, blindness and amputation have only been reported by early adulthood in youth-onset type 2 diabetes [44, 62], and rates of DKD, neuropathy, retinopathy and cardiovascular death are all currently higher in young adults with type 2 diabetes vs type 1 diabetes. Life expectancy and quality of 
life may be reduced in adults with type 1 and type 2 diabetes [63-65], but each is highly dependent on age, glycaemic control and the presence of additional complications (e.g. concomitant renal disease).

\section{Treatment}

The treatment of both type 1 and type 2 diabetes in childhood includes optimising glycaemic control and BMI through physical activity and a healthy diet $[26,27]$. However, studies demonstrating the effectiveness of lifestyle modification in youth are lacking and most youth with diabetes are not meeting blood glucose goals [47, 66]. Microvascular and macrovascular complications of diabetes are known to be influenced by hyperglycaemia [67-69] but lower average glucose levels may increase the risk of hypoglycaemia. Hypoglycaemia in type 1 diabetes has in turn been correlated with insulin resistance [70] and increased weight gain, arguing for management strategies that optimise glucose control, minimise hypoglycaemia and limit weight gain.

Type 1 diabetes The mainstay of therapy for type 1 diabetes is insulin. Intensive basal-bolus insulin regimens via multiple daily injections (MDI) of prandial and basal insulin or continuous subcutaneous insulin infusion are currently recommended for type 1 diabetes [71]. However, currently available insulins have imperfect pharmacodynamics; thus, current research includes developing ultra-rapid insulins and glucoseresponsive 'smart' insulins that have the ability to 'turn on' and 'turn off' in response to a low or high blood glucose level [72]. Insulin is also currently delivered peripherally rather than through the portal vein, causing underexposure of the liver and overexposure of the periphery to insulin, a postulated contributor to the elevated hepatic glucose output and peripheral insulin resistance, respectively, in type 1 diabetes. A hepatic-directed insulin is under study to help circumvent the peripheral delivery barrier [73].

Sensor augmented pump therapy, i.e. combining an insulin pump with a continuous glucose-monitoring system, has been shown to be superior to MDI with blood glucose selfmonitoring in reducing $\mathrm{HbA}_{1 \mathrm{c}}$ without increased frequency or severity of hypoglycaemia, provided the sensor is used $>60 \%$ of the time. These are the currently available systems (further details are provided elsewhere [74, 75]):

1. Low-glucose suspend systems - basal insulin delivery is suspended when blood glucose reaches a predefined low sensor threshold and resumes after a set period.

2. Predicted low-glucose suspend systems - basal insulin delivery is suspended when an algorithm predicts that blood glucose will drop below a specified low sensor threshold within $30 \mathrm{~min}$ and resumes once blood glucose is no longer low or falling.

3. Hybrid closed-loop systems - an overarching goal of type 1 diabetes management has been to eventually develop an artificial pancreas that integrates blood sugar measurement, an automated algorithm and a device designed to deliver one or more hormones to maintain blood glucose within a specific target range in order to minimise hypoglycaemia and hyperglycaemia and improve quality of life. The Medtronic 670G insulin pump with Guardian 3 sensor introduced in 2017 includes a hybrid closed-loop insulin delivery system that automatically adjusts basal insulin delivery every $5 \mathrm{~min}$ based on sensor glucose. Early studies show improvement in $\mathrm{HbA}_{1 \mathrm{c}}$ in both adults and adolescents without DKA or hypoglycaemia [76].
Fig. 1 Age-adjusted prevalence of complications in youth-onset diabetes by type. Data from the SEARCH for Diabetes in Youth Study [46]. Data are prevalence with $95 \%$ CIs. HTN, hypertension. This figure is available as a downloadable slide

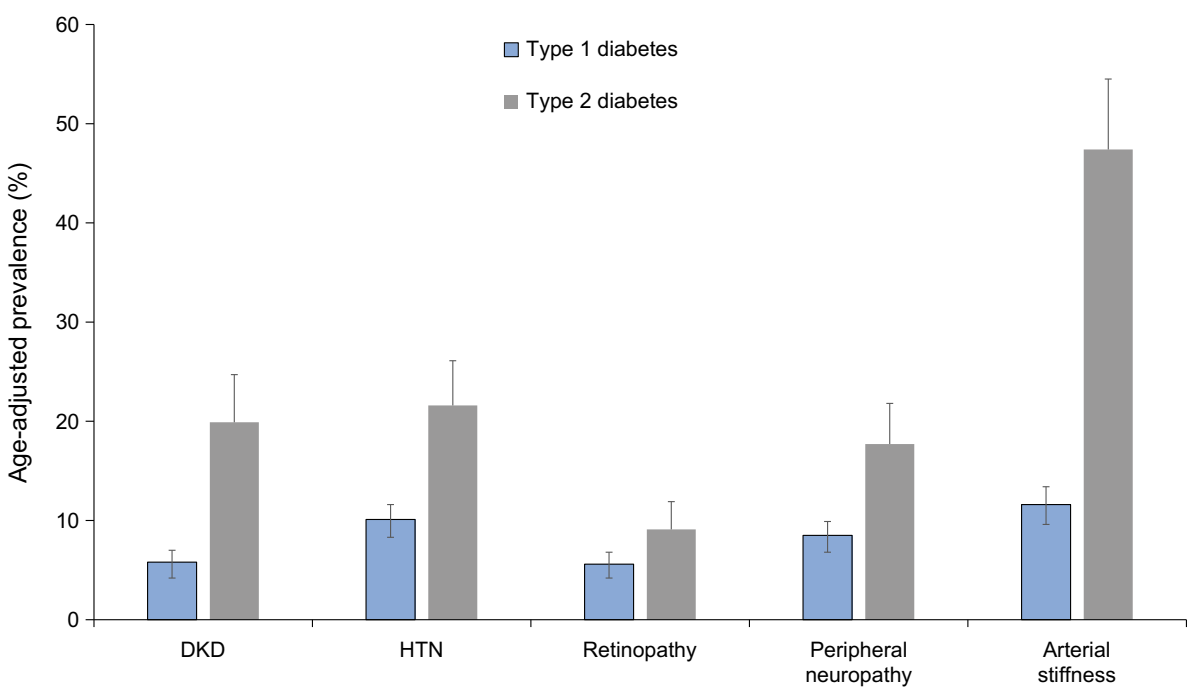


Metformin has been the most studied adjunctive agent in type 1 diabetes. A recent meta-analysis of 13 randomised controlled metformin trials in type 1 diabetes found significant improvements in BMI and reductions in insulin requirements, total cholesterol and LDL-cholesterol [77], but little or no decrease in $\mathrm{HbA}_{1 \mathrm{c}}$. Short-term paediatric data suggest similar metabolic improvements in youth [78, 79], along with improvements in insulin sensitivity [53] and vascular health on imaging [79], but data on long-term benefits of metformin in type 1 diabetes are currently lacking.

New therapies are on the horizon. Pramlintide is a synthetic analogue of amylin, which is co-secreted with insulin postprandially to inhibit glucagon release, slow gastric emptying and signal satiety and is deficient in type 1 diabetes. In adults with type 1 diabetes, pramlintide resulted in a decrease in postprandial hyperglycaemia and glucagon, $\mathrm{HbA}_{1 \mathrm{c}}$ and weight compared with insulin-only therapy $[80,81]$. Other agents being investigated in type 1 diabetes are thiazolidinediones (TZDs), glucagon-like peptide-1 (GLP-1) agonists and sodium-glucose cotransporter 2 (SGLT2) inhibitors, drugs used in type 2 diabetes [82, 83].

Continued interest remains in preventing or delaying the development of type 1 diabetes. One avenue has examined early life feeding practices hypothesised to trigger autoimmunity. Weaning to cow's milk formula free of bovine insulin decreased the incidence of diabetes-associated autoantibodies by age 3 in children with HLA-conferred susceptibility to type 1 diabetes [84], but trials weaning to a hydrolysed milk formula and delaying gluten exposure in infancy have shown no benefit $[85,86]$. TrialNet is studying hydroxychloroquine, a drug noted to improve glucose and lipid metabolism in rheumatic diseases, to prevent dysglycaemia in youth with two or more diabetes-associated antibodies (ClinicalTrials.gov no. NCT03428945). In addition, as an imbalance between autoreactive effector and regulatory $\mathrm{T}$ cells may be crucial in the breakdown of peripheral tolerance in type 1 diabetes, other experimental therapies have focused on regulatory $\mathrm{T}$ cell number and function, selective $\mathrm{T}$ cell co-stimulation modulating agents and interventions to induce tolerance [87]. Use of anti-thymocyte globulin just after type 1 diagnosis resulted in partial preservation of beta cell function and reduced $\mathrm{HbA}_{1 \mathrm{c}}$ 2 years after therapy in individuals with new-onset type 1 diabetes [88] and, recently, anti-CD3 therapy has been reported to delay progression from antibody positivity and dysglycaemia to diabetes-range hyperglycaemia by $\sim 2$ years [89].

Type 2 diabetes Using lifestyle intervention alone to achieve or maintain normal blood glucose in type 2 diabetes is difficult [90-92]. Thus, current paediatric guidelines suggest initial use of metformin, with basal insulin added for ketosis, ketonuria or an $\mathrm{HbA}_{1 \mathrm{c}}>69 \mathrm{mmol} / \mathrm{mol}(>8.5 \%)[27,93]$. However, in the TODAY study, metformin alone and metformin plus lifestyle were ineffective in maintaining durable glycaemic control in $57 \%$ and $47 \%$ of adolescents with type 2 diabetes [41], respectively. Moreover in the RISE study, neither metformin alone nor insulin followed by metformin were effective at improving beta cell function in youth with type 2 diabetes or impaired glucose tolerance [33]. While rosiglitazone enhanced the efficacy of metformin in TODAY, the combined dual therapy was still ineffective at maintaining durable control in over a third of adolescents [41]. TZDs may be a particularly helpful choice in highly insulin-resistant patients, including adolescents, with recent data showing benefit on early nephropathy when combined with SGLT2 inhibitors [94].

GLP-1 receptor agonists are approved in adults and have shown weight loss and cardiovascular benefits [95, 96]. GLP-1 is secreted by intestinal enteroendocrine L cells and the brain postprandially to increase insulin secretion and inhibit glucagon production, delay gastric emptying and signal satiety. The effects are brief because of rapid degradation by dipeptidyl peptidase-4 (DPP-4). In June 2019, liraglutide, a GLP-1 agonist, was approved in the USA for treatment of type 2 diabetes in children aged over 10 years. Approval was largely based on the results of the Ellipse trial, a randomised controlled trial of 134 youth with type 2 diabetes, which showed improved glycaemic control with add-on liraglutide compared with placebo $\left(0.64\right.$ percentage point lowering in $\mathrm{HbA}_{1 \mathrm{c}}$ vs increase of $0.42 ; 64 \%$ vs $37 \%$ of participants with $\mathrm{HbA}_{1 \mathrm{c}}<53 \mathrm{mmol} / \mathrm{mol}$ [7\%], respectively); with an overall good safety profile [97]. Weight loss was not observed, but the dose was not maximised in most participants due to the titration algorithm employed.

SGLT2 inhibitors lower blood glucose by causing decreased reabsorption of glucose from the urine. Studies in adults show reductions in $\mathrm{HbA}_{1 \mathrm{c}}$, glycaemic variability, body weight and insulin doses, increased time in the target glycaemic range, and improvements in cardiovascular risk factors and mortality compared with placebo $[95,96]$. The weight loss and glucose lowering with SGLT2 inhibitors appears less than that observed with GLP-1 receptor agonists [98], but this class of drugs appears very effective for treatment of DKD in adults [99, 100]. SGLT2 inhibitors are approved in Europe and Japan for adults with type 1 diabetes.

An emerging therapy for type 2 diabetes is metabolic bariatric surgery (MBS). MBS is recommended in adults with type 2 diabetes with obesity. MBS is also considered for less obese adults (BMI $30.0-34.9 \mathrm{~kg} / \mathrm{m}^{2}$ ) if blood glucose is inadequately controlled [101]. MBS is also now considered for adolescents with type 2 diabetes and severe obesity (BMI $\geq 35 \mathrm{~kg} / \mathrm{m}^{2}$ or BMI $\geq 120 \%$ of the 95 th percentile for age and sex) [102].

Initial MBS outcomes in youth with type 2 diabetes show weight loss and remission of diabetes [103, 104]. TeenLongitudinal Assessment of Bariatric Surgery (-LABS) is an 
observational study of youth undergoing MBS, currently with 5 years of follow-up data [105]. Of the 161 youth who underwent Roux-en Y gastric bypass (RYGB), 29 had type 2 diabetes [103]. A 94\% type 2 diabetes remission rate (defined as being free of diabetes medication and having an $\mathrm{HbA}_{1 \mathrm{c}}<48 \mathrm{mmol} / \mathrm{mol}$ [6.5\%] or a fasting blood glucose $<7.0 \mathrm{mmol} / 1[126 \mathrm{mg} / \mathrm{dl}]$ ) occurred at 3 years, with no incident type 2 diabetes cases in the youth without type 2 diabetes [103]. While direct comparisons of MBS with medical therapy have yet to occur, a retrospective comparison of youth in the TODAY study and Teen-LABS was published [106]. Over 2 years, $\mathrm{HbA}_{1 \mathrm{c}}$ fell from $51 \mathrm{mmol} / \mathrm{mol}(6.8 \%)$ on medication to $37 \mathrm{mmol} / \mathrm{mol}(5.5 \%)$ off medication in Teen-LABS, but increased from $44 \mathrm{mmol} / \mathrm{mol}(6.2 \%)$ to $62 \mathrm{mmol} / \mathrm{mol}(7.8 \%)$ on medication in TODAY. During the same time, hypertension decreased from $45 \%$ at baseline to $20 \%$ in Teen-LABS vs a near doubling in TODAY, from $22 \%$ to $41 \%$ [106]. Similarly, dyslipidaemia decreased from $72 \%$ to $24 \%$, and the proportion of youth in Teen-LABS with elevated urinary albumin excretion decreased from $26 \%$ to $5 \%$, with no change seen for either in TODAY [106]. These initial results suggest a beneficial effect of MBS on blood glucose and comorbidities. However, these results evaluated RYGB which is no longer the preferred MBS in adolescents [107] as vertical sleeve gastrectomy now accounts for more than $80 \%$ of MBS procedures in the USA [107]. Furthermore, whether bariatric surgery is superior to newer glucose-lowering medications with weight-loss benefit (i.e. GLP-1 agonists or SGLT2 inhibitors) in reducing blood glucose is not known. Two cases of youth with type 1 diabetes undergoing bariatric surgery have been reported. Weight loss similar to youth without diabetes was reported, but without improvements in glycaemic control or dependency on exogenous insulin [108].

\section{Conclusions}

The incidence and prevalence of youth-onset type 1 and 2 diabetes and its complications continue to rise. Healthy eating, physical activity and obesity prevention should be implemented for both forms of diabetes. New technologies and therapies should be considered in all adolescents with diabetes. Key areas for research include understanding: (1) the factors that predict the development of early comorbidities and complications in youth-onset diabetes; (2) the contributions of epigenetics and the environment; (3) effective strategies to reduce and treat obesity in both forms of diabetes; (4) drugs, treatments and technology that prevent, slow or reverse disease progression; and (5) the long-term impact of disease on quality of life, reproductive health and the offspring of young adults with youth-onset diabetes.

\section{Summary}

- Being overweight or obese is common in youth with type 1 or type 2 diabetes

- Identifying diabetes type is important for treatment and anticipating complications

- Comorbidities and complications are present in youth and should be screened for as per paediatric guidelines

- New medications, technology and treatments are on the horizon and should be studied in youth-onset diabetes

Funding Work at the authors' laboratories is supported by R01DK119450 from National Institutes of Health National Institute of Diabetes and Digestive and Kidney Diseases (NIDDK) to ASS and KJN.

Duality of interest The authors declare that there is no duality of interest associated with this manuscript.

Contribution statement Both authors were responsible for drafting the article and revising it critically for important intellectual content. Both authors approved the version to be published.

\section{References}

1. Jahromi MM, Eisenbarth GS (2007) Cellular and molecular pathogenesis of type 1A diabetes. Cell Mol Life Sci 64(7-8):865-872. https://doi.org/10.1007/s00018-007-6469-4

2. Defronzo RA (2009) Banting Lecture. From the triumvirate to the ominous octet: a new paradigm for the treatment of type 2 diabetes mellitus. Diabetes 58(4):773-795. https://doi.org/10.2337/db09-9028

3. Copeland KC, Zeitler P, Geffner M et al (2011) Characteristics of adolescents and youth with recent-onset type 2 diabetes: the TODAY cohort at baseline. J Clin Endocrinol Metab 96:159-167

4. Avery AR, Duncan GE (2019) Heritability of type 2 diabetes in the Washington State Twin Registry. Twin Res Hum Genet 22(2): 95-98. https://doi.org/10.1017/thg.2019.11

5. Dabelea D, Mayer-Davis EJ, Saydah S et al (2014) Prevalence of type 1 and type 2 diabetes among children and adolescents from 2001 to 2009. JAMA 311:1778-1786

6. Stanescu DE, Lord K, Lipman TH (2012) The epidemiology of type 1 diabetes in children. Endocrinol Metab Clin N Am 41:679-694

7. Harjutsalo V, Sund R, Knip M, Groop PH (2013) Incidence of type 1 diabetes in Finland. JAMA 310:427-428

8. Harjutsalo V, Sjoberg L, Tuomilehto J (2008) Time trends in the incidence of type 1 diabetes in Finnish children: a cohort study. Lancet 371:1777-1782

9. Silink M (2002) Childhood diabetes: a global perspective. Horm Res 57(Suppl 1):1-5

10. Mayer-Davis EJ, Lawrence JM, Dabelea D et al (2017) Incidence trends of type 1 and type 2 diabetes among youths, 2002-2012. N Engl J Med 376:1419-1429

11. Newhook LA, Curtis J, Hagerty D et al (2004) High incidence of childhood type 1 diabetes in the Avalon Peninsula, Newfoundland, Canada. Diabetes Care 27(4):885-888. https:// doi.org/10.2337/diacare.27.4.885 
12. Ehtisham S, Barrett TG, Shaw NJ (2000) Type 2 diabetes mellitus in UK children - an emerging problem. Diabet Med 17(12):867871. https://doi.org/10.1046/j.1464-5491.2000.00409.x

13. Amutha A, Datta M, Unnikrishnan IR et al (2011) Clinical profile of diabetes in the young seen between 1992 and 2009 at a specialist diabetes centre in south India. Prim Care Diabetes 5(4):223229. https://doi.org/10.1016/j.pcd.2011.04.003

14. Urakami T, Suzuki J, Mugishima H et al (2012) Screening and treatment of childhood type 1 and type 2 diabetes mellitus in Japan. Pediatr Endocrinol Rev 10(Suppl 1):51-61

15. Dabelea D, Pihoker C, Talton JW et al (2011) Etiological approach to characterization of diabetes type: the SEARCH for Diabetes in Youth Study. Diabetes Care 34(7):1628-1633. https://doi.org/10. 2337/dc10-2324

16. Quinn M, Fleischman A, Rosner B, Nigrin DJ, Wolfsdorf JI (2006) Characteristics at diagnosis of type 1 diabetes in children younger than 6 years. J Pediatr 148:366-371

17. Dabelea D, Rewers A, Stafford JM et al (2014) Trends in the prevalence of ketoacidosis at diabetes diagnosis: the SEARCH for diabetes in youth study. Pediatrics 133(4):e938-e945. https:// doi.org/10.1542/peds.2013-2795

18. Klingensmith GJ, Connor CG, Ruedy KJ et al (2016) Presentation of youth with type 2 diabetes in the Pediatric Diabetes Consortium. Pediatr Diabetes 17(4):266-273. https://doi.org/10. 1111/pedi.12281

19. Robinson ME, Li P, Rahme E, Simard M, Larocque I, Nakhla MM (2019) Increasing prevalence of diabetic ketoacidosis at diabetes diagnosis among children in Quebec: a population-based retrospective cohort study. CMAJ Open 7(2):E300-E305. https://doi. org/10.9778/cmajo.20190047

20. Dabelea D, Bell RA, D'Agostino RB Jr et al (2007) Incidence of diabetes in youth in the United States. JAMA 297(24):2716-2724. https://doi.org/10.1001/jama.297.24.2716

21. Minges KE, Whittemore R, Grey M (2013) Overweight and obesity in youth with type 1 diabetes. Annu Rev Nurs Res 31:47-69. https://doi.org/10.1891/0739-6686.31.47

22. DuBose SN, Hermann JM, Tamborlane WV et al (2015) Obesity in youth with type 1 diabetes in Germany, Austria, and the United States. J Pediatr 167:627-632.e621-e624

23. Bjornstad P, Maahs DM, Duca LM et al (2016) Estimated insulin sensitivity predicts incident micro- and macrovascular complications in adults with type 1 diabetes over 6 years: the coronary artery calcification in type 1 diabetes study. J Diabetes Complicat 30:586-590

24. Specht BJ, Wadwa RP, Snell-Bergeon JK, Nadeau KJ, Bishop FK, Maahs DM (2013) Estimated insulin sensitivity and cardiovascular disease risk factors in adolescents with and without type 1 diabetes. J Pediatr 162:297-301

25. Cree-Green M, Wiromrat P, Stuppy J et al (2019) Youth with Type 2 diabetes have hepatic, peripheral and adipose insulin resistance. AJP Endo 316:E186-E195

26. Zeitler P, Arslanian S, Fu J et al (2018) ISPAD Clinical Practice Consensus Guidelines 2018: type 2 diabetes mellitus in youth. Pediatr Diabetes 19(Suppl 27):28-46

27. Arslanian S, Bacha F, Grey M, Marcus MD, White NH, Zeitler P (2018) Evaluation and management of youth-onset type 2 diabetes: a position statement by the American Diabetes Association. Diabetes Care 41(12):2648-2668. https://doi.org/10.2337/dci180052

28. Klingensmith GJ, Pyle L, Arslanian S et al (2010) The presence of GAD and IA-2 antibodies in youth with a type 2 diabetes phenotype: results from the TODAY study. Diabetes Care 33(9):19701975. https://doi.org/10.2337/dc10-0373

29. Turner R, Stratton I, Horton V et al (1997) UKPDS 25: autoantibodies to islet-cell cytoplasm and glutamic acid decarboxylase for prediction of insulin requirement in type 2 diabetes. UK
Prospective Diabetes Study Group. Lancet 350(9087):12881293. https://doi.org/10.1016/s0140-6736(97)03062-6

30. Couper JJ, Haller MJ, Greenbaum CJ et al (2018) ISPAD Clinical Practice Consensus Guidelines 2018: stages of type 1 diabetes in children and adolescents. Pediatr Diabetes 19(Suppl 27):20-27

31. Ziegler AG, Rewers M, Simell O et al (2013) Seroconversion to multiple islet autoantibodies and risk of progression to diabetes in children. JAMA 309(23):2473-2479. https://doi.org/10.1001/ jama.2013.6285

32. Sosenko JM, Skyler JS, Palmer JP et al (2013) The prediction of type 1 diabetes by multiple autoantibody levels and their incorporation into an autoantibody risk score in relatives of type 1 diabetic patients. Diabetes Care 36(9):2615-2620. https://doi.org/10.2337/ dc13-0425

33. The RISE Consortium (2018) Impact of insulin and metformin versus metformin alone on beta-cell function in youth with impaired glucose tolerance or recently diagnosed type 2 diabetes. Diabetes Care 41: 1717-1725

34. RISE Consortium (2018) Metabolic contrasts between youth and adults with impaired glucose tolerance or recently diagnosed type 2 diabetes: II. Observations using the oral glucose tolerance test. Diabetes Care 41:1707-1716

35. RISE Consortium (2018) Metabolic contrasts between youth and adults with impaired glucose tolerance or recently diagnosed type 2 diabetes: I. Observations using the hyperglycemic clamp. Diabetes Care 41:1696-1706

36. RISE Consortium (2019) Effects of treatment of impaired glucose tolerance or recently diagnosed type 2 diabetes with metformin alone or in combination with insulin glargine on $\beta$-cell function: comparison of responses in youth and adults. Diabetes 68:1670-1680

37. Bacha F, Gungor N, Lee S, Arslanian SA (2013) Progressive deterioration of beta-cell function in obese youth with type 2 diabetes. Pediatr Diabetes 14(2):106-111. https://doi.org/10.1111/j.13995448.2012.00915.x

38. D'Adamo E, Caprio S (2011) Type 2 diabetes in youth: epidemiology and pathophysiology. Diabetes Care 34(Suppl 2):S161S165

39. Druet C, Tubiana-Rufi N, Chevenne D, Rigal O, Polak M, LevyMarchal C (2006) Characterization of insulin secretion and resistance in type 2 diabetes of adolescents. J Clin Endocrinol Metab 91(2):401-404. https://doi.org/10.1210/jc.2005-1672

40. Zeitler P, Epstein L, Grey M et al (2007) Treatment options for type 2 diabetes in adolescents and youth: a study of the comparative efficacy of metformin alone or in combination with rosiglitazone or lifestyle intervention in adolescents with type 2 diabetes. Pediatr Diabetes 8(2):74-87. https://doi.org/10.1111/j. 1399-5448.2007.00237.x

41. Zeitler P, Hirst K, Pyle L et al (2012) A clinical trial to maintain glycemic control in youth with type 2 diabetes. N Engl J Med 366(24):2247-2256. https://doi.org/10.1056/NEJMoa1109333

42. Sànchez-Santos R, Sabench Pereferrer F, Estèvez Fernandez $S$ et al (2013) Is the morbid obesity surgery profitable in times of crisis? A cost-benefit analysis of bariatric surgery. Cir Esp 91: 476-484 [article in Spanish]

43. Kahn SE, Haffner SM, Heise MA et al (2006) Glycemic durability of rosiglitazone, metformin, or glyburide monotherapy. N Engl J Med 355(23):2427-2443. https://doi.org/10.1056/ NEJMoa066224

44. Kavey RE, Allada V, Daniels SR et al (2007) Cardiovascular risk reduction in high-risk pediatric patients: a scientific statement from the American Heart Association Expert Panel on Population and Prevention Science; the Councils on Cardiovascular Disease in the Young, Epidemiology and Prevention, Nutrition, Physical Activity and Metabolism, High Blood Pressure Research, Cardiovascular Nursing, and the Kidney in Heart Disease; and the Interdisciplinary Working 
Group on Quality of Care and Outcomes Research. J Cardiovasc Nurs 22(3):218-253. https://doi.org/10.1097/01.JCN 0000267827.50320 .85

45. Expert panel on integrated guidelines for cardiovascular health and risk reduction in children and adolescents (2011) Expert panel on integrated guidelines for cardiovascular health and risk reduction in children and adolescents: summary report. Pediatrics 128(Suppl 5): S213-S256

46. Dabelea D, Stafford JM, Mayer-Davis EJ et al (2017) Association of type 1 diabetes vs type 2 diabetes diagnosed during childhood and adolescence with complications during teenage years and young adulthood. JAMA 317(8):825-835. https://doi.org/10. 1001/jama.2017.0686

47. Hamman RF, Bell RA, Dabelea D et al (2014) The SEARCH for Diabetes in Youth study: rationale, findings, and future directions. Diabetes Care 37(12):3336-3344. https://doi.org/10.2337/dc140574

48. Snell-Bergeon JK, Nadeau K (2012) Cardiovascular disease risk in young people with type 1 diabetes. J Cardiovasc Transl Res 5: 446-462

49. Nadeau KJ, Reusch JE (2011) Cardiovascular function/ dysfunction in adolescents with type 1 diabetes. Curr Diab Rep 11:185-192

50. Bjornstad P, Truong U, Pyle L et al (2016) Youth with type 1 diabetes have worse strain and less pronounced sex differences in early echocardiographic markers of diabetic cardiomyopathy compared to their normoglycemic peers: a RESistance to InSulin in Type 1 ANd Type 2 diabetes (RESISTANT) Study. J Diabetes Complicat 30(6):1103-1110. https://doi.org/10.1016/j.jdiacomp. 2016.04.008

51. Bjornstad P, Snell-Bergeon JK, Nadeau KJ, Maahs DM (2015) Insulin sensitivity and complications in type 1 diabetes: new insights. World J Diabetes 6(1):8-16. https://doi.org/10.4239/ wjd.v6.i1.8

52. Bjornstad P, Cree-Green M, Baumgartner A et al (2015) Renal function is associated with peak exercise capacity in adolescents with type 1 diabetes. Diabetes Care 38(1):126-131. https://doi. org/10.2337/dc14-1742

53. Cree-Green M, Bergman BC, Cengiz E et al (2019) Metformin improves peripheral insulin sensitivity in youth with type 1 diabetes. J Clin Endocrinol Metab 104:3265-3278

54. Nadeau KJ, Zeitler PS, Bauer TA et al (2009) Insulin resistance in adolescents with type 2 diabetes is associated with impaired exercise capacity. J Clin Endocrinol Metab 94:3687-3695

55. Shah AS, El Ghormli L, Gidding SS et al (2018) Prevalence of arterial stiffness in adolescents with type 2 diabetes in the TODAY cohort: relationships to glycemic control and other risk factors. J Diabetes Complicat 32:740-745

56. Bjornstad P, Truong U, Dorosz JL et al (2016) Cardiopulmonary dysfunction and adiponectin in adolescents with type 2 diabetes. $\mathrm{J}$ Am Heart Assoc 5:e002804

57. Bacha F, Gidding SS, Pyle L et al (2016) Relationship of cardiac structure and function to cardiorespiratory fitness and lean body mass in adolescents and young adults with type 2 diabetes. $\mathrm{J}$ Pediatr 177:159-166 e151

58. Levitt Katz L, Gidding SS, Bacha F et al (2015) Alterations in left ventricular, left atrial, and right ventricular structure and function to cardiovascular risk factors in adolescents with type 2 diabetes participating in the TODAY clinical trial. Pediatr Diabetes 16(1): 39-47. https://doi.org/10.1111/pedi.12119

59. Shah AS, Khoury PR, Dolan LM et al (2011) The effects of obesity and type 2 diabetes mellitus on cardiac structure and function in adolescents and young adults. Diabetologia 54(4):722-730. https://doi.org/10.1007/s00125-010-1974-7
60. Nadeau KJ, Klingensmith G, Zeitler P (2005) Type 2 diabetes in children is frequently associated with elevated alanine aminotransferase. J Pediatr Gastroenterol Nutr 41:94-98

61. Newton KP, Hou J, Crimmins NA et al (2016) Prevalence of prediabetes and type 2 diabetes in children with nonalcoholic fatty liver disease. JAMA Pediatr 170:e161971

62. Dart AB, Martens PJ, Rigatto C, Brownell MD, Dean HJ, Sellers EA (2014) Earlier onset of complications in youth with type 2 diabetes. Diabetes Care 37(2):436-443. https://doi.org/10.2337/ dc13-0954

63. Tancredi M, Rosengren A, Svensson AM et al (2015) Excess mortality among persons with type 2 diabetes. N Engl J Med 373:1720-1732

64. Livingstone SJ, Levin D, Looker HC et al (2015) Estimated life expectancy in a Scottish cohort with type 1 diabetes, 2008-2010. JAMA 313(1):37-44. https://doi.org/10.1001/jama.2014.16425

65. Rawshani A, Rawshani A, Franzen S et al (2017) Mortality and cardiovascular disease in type 1 and type 2 diabetes. $N$ Engl J Med 376(15):1407-1418. https://doi.org/10.1056/NEJMoa1608664

66. Wood JR, Miller KM, Maahs DM et al (2013) Most youth with type 1 diabetes in the T1D Exchange Clinic Registry do not meet American Diabetes Association or International Society for Pediatric and Adolescent Diabetes clinical guidelines. Diabetes Care 36(7):2035-2037. https://doi.org/10.2337/dc12-1959

67. Nathan DM, Genuth S, Lachin J et al (1993) The effect of intensive treatment of diabetes on the development and progression of long-term complications in insulin-dependent diabetes mellitus. $\mathrm{N}$ Engl J Med 329(14):977-986. https://doi.org/10.1056/ NEJM199309303291401

68. Barr CC (2001) Retinopathy and nephropathy in patients with type 1 diabetes four years after a trial of intensive insulin therapy, by The Diabetes Control and Complications Trial/Epidemiology of Diabetes Interventions and Complications Research Group. N. Engl. J. Med 342:381-9, 2000. Surv Ophthalmol 45: 459-460, 5, https://doi.org/10.1016/s0039-6257(01)00187-4

69. UK Prospective Diabetes Study (UKPDS) Group (1998) Effect of intensive blood-glucose control with metformin on complications in overweight patients with type 2 diabetes (UKPDS 34). UK Prospective Diabetes Study (UKPDS) Group. Lancet 352:854 865

70. Chan CL, Pyle L, Morehead R, Baumgartner A, Cree-Green M, Nadeau KJ (2017) The role of glycemia in insulin resistance in youth with type 1 and type 2 diabetes. Pediatr Diabetes 18(6):470 477. https://doi.org/10.1111/pedi.12422

71. DiMeglio LA, Acerini CL, Codner E et al (2018) ISPAD Clinical Practice Consensus Guidelines 2018: glycemic control targets and glucose monitoring for children, adolescents, and young adults with diabetes. Pediatr Diabetes 19(Suppl 27):105-114

72. Rege NK, Phillips NFB, Weiss MA (2017) Development of glucose-responsive 'smart' insulin systems. Curr Opin Endocrinol Diabetes Obes 24:267-278

73. Geho WB, Geho HC, Lau JR, Gana TJ (2009) Hepatic-directed vesicle insulin: a review of formulation development and preclinical evaluation. J Diabetes Sci Technol 3(6):1451-1459. https:/ doi.org/10.1177/193229680900300627

74. Rodbard D (2017) Continuous glucose monitoring: a review of recent studies demonstrating improved glycemic outcomes. Diabetes Technol Ther 19(S3):S25-S37. https://doi.org/10.1089/ dia.2017.0035

75. De Ridder F, den Brinker M, De Block C (2019) The road from intermittently scanned glucose monitoring to hybrid closed-loop systems: Part A. Keys to success: subject profiles, choice of systems, education. Ther Adv Endocrinol Metab 10: 2042018819865399 
76. Weaver KW, Hirsch IB (2018) The hybrid closed-loop system: evolution and practical applications. Diabetes Technol Ther 20(S2):S216-S223. https://doi.org/10.1089/dia.2018.0091

77. Meng H, Zhang A, Liang Y, Hao J, Zhang X, Lu J (2018) Effect of metformin on glycaemic control in patients with type 1 diabetes: a meta-analysis of randomized controlled trials. Diabetes Metab Res Rev 34:e2983

78. Libman IM, Miller KM, DiMeglio LA et al (2015) Effect of metformin added to insulin on glycemic control among overweight/obese adolescents with type 1 diabetes: a Randomized Clinical Trial. JAMA 314:2241-2250

79. Bjornstad P, Schafer M, Truong U et al (2018) Metformin improves insulin sensitivity and vascular health in youth with type 1 diabetes mellitus. Circulation 138(25):2895-2907. https://doi. org/10.1161/CIRCULATIONAHA.118.035525

80. Riddle MC, Nahra R, Han J et al (2018) Control of postprandial hyperglycemia in type 1 diabetes by 24-hour fixed-dose coadministration of pramlintide and regular human insulin: a randomized, two-way crossover study. Diabetes Care 41(11):2346-2352. https://doi.org/10.2337/dc18-1091

81. Qiao YC, Ling W, Pan YH et al (2017) Efficacy and safety of pramlintide injection adjunct to insulin therapy in patients with type 1 diabetes mellitus: a systematic review and meta-analysis. Oncotarget 8(39):66504-66515. https://doi.org/10.18632/ oncotarget. 16008

82. Janzen KM, Steuber TD, Nisly SA (2016) GLP-1 agonists in type 1 diabetes mellitus. Ann Pharmacother 50(8):656-665. https://doi. org/10.1177/1060028016651279

83. McCrimmon RJ, Henry RR (2018) SGLT inhibitor adjunct therapy in type 1 diabetes. Diabetologia 61:2126-2133

84. Vaarala O, Ilonen J, Ruohtula T et al (2012) Removal of bovine insulin from cow's milk formula and early initiation of beta-cell autoimmunity in the FINDIA pilot study. Arch Pediatr Adolesc Med 166(7):608-614. https://doi.org/10.1001/archpediatrics.2011.1559

85. Hummel S, Pfluger M, Hummel M, Bonifacio E, Ziegler AG (2011) Primary dietary intervention study to reduce the risk of islet autoimmunity in children at increased risk for type 1 diabetes: the BABYDIET study. Diabetes Care 34:1301-1305

86. Goodwin G (2019) Type 1 diabetes mellitus and celiac disease: distinct autoimmune disorders that share common pathogenic mechanisms. Horm Res Paediatr:1-8. https://doi.org/10.1159/ 000503142

87. Yu H, Paiva R, Flavell RA (2018) Harnessing the power of regulatory T-cells to control autoimmune diabetes: overview and perspective. Immunology 153(2):161-170. https://doi.org/10.1111/imm.12867

88. Haller MJ, Long SA, Blanchfield JL et al (2019) Low-dose antithymocyte globulin preserves c-peptide, reduces $\mathrm{HbA}_{1 \mathrm{c}}$, and increases regulatory to conventional T-cell ratios in new-onset type 1 diabetes: two-year clinical trial data. Diabetes 68(6): 1267-1276. https://doi.org/10.2337/db19-0057

89. Herold KC, Bundy BN, Long SA et al (2019) An anti-CD3 antibody, teplizumab, in relatives at risk for type 1 diabetes. $\mathrm{N}$ Engl $\mathrm{J}$ Med 381(7):603-613. https://doi.org/10.1056/NEJMoa1902226

90. Willi SM, Martin K, Datko FM, Brant BP (2004) Treatment of type 2 diabetes in childhood using a very-low-calorie diet. Diabetes Care 27(2):348-353. https://doi.org/10.2337/diacare.27.2.348

91. Wittmeier KD, Wicklow BA, Sellers EA, Griffith AT, Dean HJ, McGavock JM (2012) Success with lifestyle monotherapy in youth with new-onset type 2 diabetes. Paediatr Child Health 17: 129-132

92. Burns N, Finucane FM, Hatunic M et al (2007) Early-onset type 2 diabetes in obese white subjects is characterised by a marked defect in beta cell insulin secretion, severe insulin resistance and a lack of response to aerobic exercise training. Diabetologia 50(7): 1500-1508. https://doi.org/10.1007/s00125-007-0655-7

93. Zeitler P, Fu J, Tandon N et al (2014) ISPAD Clinical Practice Consensus Guidelines 2014. Type 2 diabetes in the child and adolescent. Pediatr Diabetes 15(Suppl 20):26-46

94. Han E, Shin E, Kim G et al (2018) Combining SGLT2 inhibition with a thiazolidinedione additively attenuate the very early phase of diabetic nephropathy progression in type 2 diabetes mellitus. Front Endocrinol 9:412

95. Marso SP, Daniels GH, Brown-Frandsen K et al (2016) Liraglutide and cardiovascular outcomes in type 2 diabetes. N Engl J Med 375(4):311-322. https://doi.org/10.1056/ NEJMoa1603827

96. Zinman B, Wanner C, Lachin JM et al (2015) Empagliflozin, cardiovascular outcomes, and mortality in type 2 diabetes. $\mathrm{N}$ Engl J Med 373(22):2117-2128. https://doi.org/10.1056/ NEJMoa1504720

97. Klein DJ, Battelino T, Chatterjee DJ, Jacobsen LV, Hale PM, Arslanian S (2014) Liraglutide's safety, tolerability, pharmacokinetics, and pharmacodynamics in pediatric type 2 diabetes: a randomized, double-blind, placebo-controlled trial. Diabetes Technol Ther 16(10): 679-687. https://doi.org/10.1089/dia.2013.0366

98. de Wit HM, Te Groen M, Rovers MM, Tack CJ (2016) The placebo response of injectable GLP-1 receptor agonists vs. oral DPP-4 inhibitors and SGLT-2 inhibitors: a systematic review and metaanalysis. Br J Clin Pharmacol 82:301-314

99. Neal B, Perkovic V, Mahaffey KW et al (2017) Canagliflozin and cardiovascular and renal events in type 2 diabetes. N Engl J Med 377(7):644-657. https://doi.org/10.1056/NEJMoa1611925

100. Wanner C, Inzucchi SE, Lachin JM et al (2016) Empagliflozin and progression of kidney disease in type 2 diabetes. N Engl J Med 375(4):323-334. https://doi.org/10.1056/NEJMoa1515920

101. Rubino F, Nathan DM, Eckel RH et al (2016) Metabolic surgery in the treatment algorithm for type 2 diabetes: a joint statement by international diabetes organizations. Surg Obes Relat Dis 12(6): 1144-1162. https://doi.org/10.1016/j.soard.2016.05.018

102. Pratt JS, Lenders CM, Dionne EA et al (2009) Best practice updates for pediatric/adolescent weight loss surgery. Obesity 17: 901-910

103. Inge TH, Courcoulas AP, Jenkins TM et al (2016) Weight loss and health status 3 years after bariatric surgery in adolescents. N Engl J Med 374(2):113-123. https://doi.org/10.1056/NEJMoa1506699

104. Inge TH, Miyano G, Bean J et al (2009) Reversal of type 2 diabetes mellitus and improvements in cardiovascular risk factors after surgical weight loss in adolescents. Pediatrics 123(1):214-222. https://doi.org/10.1542/peds.2008-0522

105. Inge TH, Courcoulas AP, Jenkins TM et al (2019) Five-year outcomes of gastric bypass in adolescents as compared with adults. N Engl J Med 380(22):2136-2145. https://doi.org/10. 1056/NEJMoa1813909

106. Inge TH, Laffel LM, Jenkins TM et al (2018) Comparison of surgical and medical therapy for type 2 diabetes in severely obese adolescents. JAMA Pediatr 172:452-460

107. Inge TH, Coley RY, Bazzano LA et al (2018) Comparative effectiveness of bariatric procedures among adolescents: the PCORnet bariatric study. Surg Obes Relat Dis 14(9):1374-1386. https://doi. org/10.1016/j.soard.2018.04.002

108. Chuang J, Zeller MH, Inge T, Crimmins N (2013) Bariatric surgery for severe obesity in two adolescents with type 1 diabetes. Pediatrics 132:e1031-e1034

Publisher's note Springer Nature remains neutral with regard to jurisdictional claims in published maps and institutional affiliations. 